BERICHTE UBER DIE VERHANDLUNGEN DER SÄCHSISCHEN AKADEMIE DER WISSENSCHAFTEN ZU LEIPZIG

Philologisch-historische Klasse

Band $103 \cdot$ Heft 6

GERTRAUD MÜLLER und THEODOR FRINGS

\author{
DIE ENTSTEHUNG \\ DER DEUTSCHEN daß-SÄTZE
}

A K A D E M I E-V ERLA G B E R L I N 1959 


\title{
BERICHTE ÜBER DIE VERHANDLUNGEN DER SÄCHSISCHEN AKADEMIE DER WISSENSCHAFTEN ZU LEIPZIG
}

\author{
PHILOLOGISCH-HISTORISCHE KLASSE
}

Band 97

Heft 1 Prof. Dr. Theodor Frings, Antike und Christentum an der Wiege der deutschen Sprache 36 Seiten $-8^{\circ}-1949-$ DM 3,- (vergriffen)

Heft 2 .Prof. Dr. Friedrich Welier, Zum mongolischen Tanjur 36 Seiten $-8^{\circ}-1949-$ DM 4,75 (vergriffen)

Heft 3 Prof. Dr. Walter BaEtKe, Die Götterlehre der Snorra-Edda Nachdruck - 68 Seiten $-8^{\circ}-1952-$ DM 6,30 (vergriffen)

Heft 4 Prof. Dr. Carl Brockelmann, Abessinische Studien 60 Seiten $-8^{\circ}-1950-$ DM $6,-$ (vergriffen)

Heft 5 Prof. Dr. Wilhelm Schubart, Griechische literarische Papyri 108 Seiten $-8^{\circ}-1950-$ DM 13,25 (vergriffen)

Heft 6 Prof. Dr. Franz Dornseirf, Verschmähtes zu Vergil, Horaz und Properz Nachdruck - 108 Seiten $-8^{\circ}-1951$ - DM 11,50 (vergriffen)

Heft 7 Prof. Dr. Whrner Krauss, Altspanische Drucke im Besitz der außerspanischen Bibliotheken 112 Seiten $-8^{\circ}-1951-$ DM 10,50 (vergriffen)

Heft 8 Prof. Dr. Martin Lrntzed, Liebe und Tod bei Heinrich von Kleist 76 Seiten $-8^{\circ}-1950-$ DM 3,50 (vergriffen)

Band 98

Heft 1 Prof. Dr. Friedrich ZdCKkr, Freundschaftsbewährung in der neuen attischen Komödie. Ein Kapitel hellenistischer Ethik und Humanität 38 Seiten $-8^{\circ}-1950-$ DM 3,60 (vergriffen)

Heft 2 Prof. Dr. Friedrion Beren, Vorgeschichtliche Felsbilder in Karelien und West-Sibirien 16 Seiten -4 Tafeln $-8^{\circ}-1950-$ DM 3,50 (vergriffen)

Heft 3 Dr. JACOB JATZwauk, Sorbische Bibliographie, 2. Auflage

$$
\mathrm{XX} \text { und } 500 \text { Seiten }-8^{\circ}-1052-\mathrm{DM} 16,- \text { (vergriffen) }
$$

Heft 4 Prof. Dr. Oтto Ersseredt, El im ugaritischen Pantheon 84 Seiten - 1 Tafel als Frontispicium - $8^{\circ}-1951$ - DM 9, - (vergriffen)

Heft 5 Prof. Dr. PaUl Threme, Studien zur indogermanischen Wortkunde Nachdruck -78 Seiten $-8^{\circ}-1952-$ DM 9,60

Heft 6 Prof. Dr. Walter BaEtke, Christliches Lehngut in der Sagareligion. Das Svoldr-Problem

$$
\text { Nachdrwck - } 135 \text { Seiten }-8^{\circ}-1952-\text { DM 5,50 (vergriffen) }
$$

Band 99

Heft 1 Prof. Dr. Karl Barwick, Caesars bellum civile (Tendenz, Abfassungszeit und Stil) 178 Selten $-8^{\circ}-1951-$ DM 11,70 (vergriffen) 